\title{
Hyaline Body Myopathy: Adulthood Manifestations
}

\author{
Mubeen F. Rafay, William Halliday, Vera Bril
}

\begin{abstract}
Background: Hyaline body myopathy (HBM) is a rare chronic nonprogressive congenital myopathy, with variable patterns of inheritance. Methods: We describe a patient with congenital HBM with progression of weakness and increasing muscle pain in adulthood. Three muscle biopsies, done at various times in her life, are reported. Results: Symptoms started during childhood; however, as an adult, following a period of stability with no progression of the disease, the patient became symptomatic with worsening proximal limb weakness, severe aching pain and hypertrophy of calves. Moderate elevations of serum creatine kinase and myopathic features were noted on electrophysiologic testing. Muscle pathology showed significant fatty infiltration of skeletal muscle and increased number of fibers with internal nuclei. Histology demonstrated the presence of subsarcolemmal, well-delineated hyaline areas, which on histochemical studies was shown to be limited to type1 fibers. The hyaline bodies were dark with pH 4.2 ATPase and with immunohistochemical studies reacted only with myosin heavy chain slow. Electron microscopy showed the hyaline bodies to be composed of nonmembrane bound, fairly even sized granular material, which merged with the adjacent myofibrils. Earlier muscle biopsies, done during childhood, also revealed presence of similar subsarcolemmal hyaline deposits. Conclusion: There appears to be a pattern of presentation with adulthood progression in HBM, which has not been described before. Further case studies are required to understand the clinical progression in HBM.
\end{abstract}

RÉSUMÉ: Manifestations de la myopathie à corps hyalins chez l'adulte. Introduction: La myopathie à corps hyalins (MCH) est une myopathie congénitale chronique rare qui ne progresse pas. Son mode d'hérédité est variable. Méthodes: Nous décrivons le cas d'une patiente atteinte de MCH congénitale, dont la faiblesse musculaire a progressé à l'âge adulte, associée à des douleurs musculaires de plus en plus importantes. Nous rapportons les constatations faites sur trois échantillons de tissus provenant de biopsies musculaires effectuées à différents moments de sa vie. Résultats: Ses symptômes sont apparus dans l'enfance. À l'âge adulte, après une période stable sans progression de la maladie, elle a présenté une faiblesse musculaire proximale de plus en plus importante au niveau des membres, des douleurs sévères et de l'hypertrophie des mollets. La créatine phosphokinase était modérément augmentée et des signes de myopathie étaient présents à l'électromyogramme. L'examen anatomopathologique du tissu musculaire a montré une infiltration graisseuse importante des muscles squelettiques et une augmentation du nombre de fibres musculaires ayant des noyaux internes et la présence de zones hyalines sous-sarcolemmiques bien délimitées qui, à l'étude histochimique, étaient limitées aux fibres de type 1. Les corps hyalins étaient foncés à la coloration par l'ATPase à pH 4,2 et à l'immunohistochimie réagissaient seulement avec la chaîne lourde de la myosine. La microscopie électronique a montré que les corps hyalins étaient composés de matière granuleuse de taille égale, non fixée à la membrane, liée aux myofibrilles adjacentes. Des biopsies musculaires faites dans l'enfance ont également montré la présence de dépôts hyalins sous-sarcolemmiques semblables. Conclusion: Il semble y avoir un autre mode de présentation de la $\mathrm{MCH}$ avec progression à l'âge adulte, qui n'a jamais été décrit antérieurement et dont la progression ne pourra être comprise que par l'étude d'autres cas ayant une évolution similaire.

Can. J. Neurol. Sci. 2005; 32: 253-256

Hyaline body myopathy (HBM) is a rare, chronic nonprogressive myopathy of childhood. ${ }^{1}$ It was first described, by Cancilla et al in 1971, as "familial myopathy with probable lysis of myofibrils in type I fibers", in two siblings, ages five and two years. ${ }^{2}$ A total of 29 patients have been reported in the literature since then, including an affected family recently published by Bohlega and colleagues. ${ }^{1-9}$ Variable modes of inheritance including autosomal dominant, autosomal recessive and sporadic patterns have been reported. ${ }^{2-7}$ Recently, two causative genes, including MYH7 missense mutation and a gene locus at chromosome 3p22.2-p21.32, were identified. ${ }^{89}$ Hyaline body myopathy has a diverse clinical spectrum, with onset in either childhood or adulthood, varying from mild generalized weakness with some accentuation in the proximal group of muscles to predominant scapuloperoneal or limb-girdle distribution of weakness. Mild to moderate elevations of serum creatine kinase have been reported. Electromyography demonstrates nonspecific myopathic features. ${ }^{1}$ The typical histopathological and immunohistochemical features, exclusively affecting the type I

From the Division of Neurology, Department of Pediatrics, (MFR); Division of Pathology (Neuropathology), The Hospital for Sick Children, (WH); Division of Neurology, (VB); University Health Network, Toronto, Ontario, Canada

ReCeIVed November 27, 2003. AcCePTED In FINAL FORm DeCEMBER 22, 2004

Reprint requests to: Mubeen F. Rafay, Division of Neurology, Hospital for Sick

Children, 555 University Avenue, Toronto, Ontario, Canada, M5G 1X8 
Table: Antibodies (Ab) used for immunohistochemical studies.

\begin{tabular}{llll}
\hline Ab & Clone & Dilution & Company \\
SMMS (Myosin heavy chains, smooth muscle) & SMMS-1 & $1 / 200$ & Biogenex (distributor is ESBE Scientific) \\
Myosin & MY-32 & $1 / 100$ & Signet Laboratories Inc. (distributor is I.D. Labs) \\
MHCd (Myosin heavy chain, developmental - frozen) & RNMy/9D2 & neat & Novocastra (distributor is Vector) \\
MHCf (Myosin heavy chain,fast - frozen) & WB-MHCf & $1 / 40$ & Novocastra (distributor is Vector) \\
MHCn (Myosin heavy chain, neonatal - frozen) & WB-MHCn & $1 / 10$ & Novocastra (distributor is Vector) \\
MHCs (Myosin heavy chain, slow - frozen) & WB-MHCs & $1 / 80$ & Novocastra (distributor is Vector) \\
\hline
\end{tabular}

fibers, allow for the diagnosis. Type I fibers demonstrate typical subsarcolemmal, eosinophilic glass-like regions referred to as "hyaline bodies". Hyaline bodies show significant reactivity to myofibrillar ATPase after acid pre-incubation ${ }^{1,4,5}$ and with immunohistochemistry, show intense reactivity with only slow myosin heavy chain (MHC). ${ }^{6}$ Electron microscopy of the affected areas show a lack of myofibrils and a uniform, finely granular matrix, sometimes suggesting a filamentous nature, containing few scattered nuclei and mitochondria. Unaffected regions show normal myofibrils and the transition from normal to abnormal areas tends to be abrupt. ${ }^{1,4-6}$ It has been postulated that hyaline bodies may be products of degeneration of MHC slow. ${ }^{6}$ We describe a patient with this chronic non progressive congenital myopathy with progression of weakness and increasing muscle pain in adulthood.

\section{Case Report}

The patient is a 52-year-old Italian woman, who presented with difficulty walking and frequent falls since age two years. She continued to have difficulty ambulating with prominent hip girdle weakness until age nine. Skeletal muscle biopsy, done at age four, reported histopathology suggestive of primary muscular dystrophy. Muscle biopsy was repeated at age nine, which also reported only minimal inflammatory change. No mention of subsarcolemmal deposits or hyaline bodies was found in the earlier reports. Interestingly, the patient reported gradual improvement from age five to nine, with no reported weakness or walking difficulties till about the age of 49 years when she again developed difficulty with walking as well as lifting things above her shoulders. At that time she also reported significant pain in her hips, shoulders and neck with worsening of symptoms after exertion. Pain was described as an aching pain and was rated as 7 out of 10 in intensity on a visual analogue scale (VAS). ${ }^{10}$ She had to quit her job as a grocery clerk because of progressive worsening of her symptoms with time. She did not have ocular or bulbar symptoms. Her family history was significant for early deaths in two of her father's brothers, at ages three and seven years, possibly due to a neuromuscular disease. She has two sisters and one brother, who are reported healthy.

Her general examination was unremarkable. On neurologic examination, she had a broad-based gait with some pelvic tilt and winging of the scapulae. She had hypertrophy of her forearms and calves bilaterally and proximal weakness in her limbs. Manual muscle testing according to the Medical Research Council for muscle power grading (British system, MRC scale, M1-M5) ${ }^{11}$ revealed weakness of grade 4 in deltoids, infraspinatus, biceps, hip flexors and hamstrings bilaterally. The remainder of the muscles in the limbs, neck, trunk and face were normal. Muscle tenderness was absent and the tone was normal. Reflexes were diminished in the lower limbs and normal in the upper limbs. Plantar reflexes were down going bilaterally. The cranial nerve examination, co-ordination, sensation and autonomic functions were normal.

Her laboratory investigations showed an elevated serum creatine kinase to $748 \mathrm{U} / \mathrm{L}$ (normal up to $130 \mathrm{U} / \mathrm{L}$ ) and serum aldolase $9.5 \mathrm{U} / \mathrm{L}$ (normal up to $7.6 \mathrm{U} / \mathrm{L}$ ). Her complete blood count, erythrocyte sedimentation rate, serum lactate, thyroid stimulating hormone, transaminases and genetic testing for facioscapulohumeral, Duchenne's and Becker's muscular dystrophy were normal. Electrophysiologic studies showed normal motor and sensory nerve conduction studies. Needle electromyography of the deltoid and quadriceps femoris muscle demonstrated a mixed pattern of motor unit potentials with low amplitude and brief duration polyphasic motor units intermingled with high amplitude and long duration polyphasic motor units. Recruitment was full with minimal voluntary effort and abnormal spontaneous activity, including myotonia, was absent.

\section{Muscle Pathology}

The earlier muscle biopsies (paraffin embedded material) from the years 1954 and 1960 were reviewed. Both revealed presence of subsarcolemmal hyaline bodies. (Figure A and B).

A muscle biopsy was taken from the left biceps brachii. Biopsy portions were a) fixed in formalin (light microscopy), b) snap frozen for histochemistry and immunohistochemistry and c) fixed and processed as per standard electron microscopy techniques. Using standard histochemical protocols, cryostat sections were processed for hematoxylin and eosin, modified Gomori trichrome, Periodic acid Schiff, oxidative enzymes, Oil red O, Congo Red, and ATPase at pH 9.4 and 4.2. Immunohistochemical studies used antibodies against laminin, alpha-sarcoglycans, dystrophins 1, 2 and 3, beta- APP (amyloid precursor protein), alpha beta crystalline, actin, myoglobin, desmin, and a series of myosins (Table).

Microscopy of the skeletal muscle showed significant fatty infiltration of the perimysium and endomysium, which divided the muscle into groups or islands of muscle fibers. The endomysial connective tissue was unremarkable and scattered foci of lymphocytes were noted. Increased numbers of fibers with internal nuclei were also seen. The histochemical studies showed type I fiber predominance $(71 \%)$ and demonstrated the presence of subsarcolemmmal hyaline areas in $10 \%$ of the type I fibers. A smaller population of type I fibers 


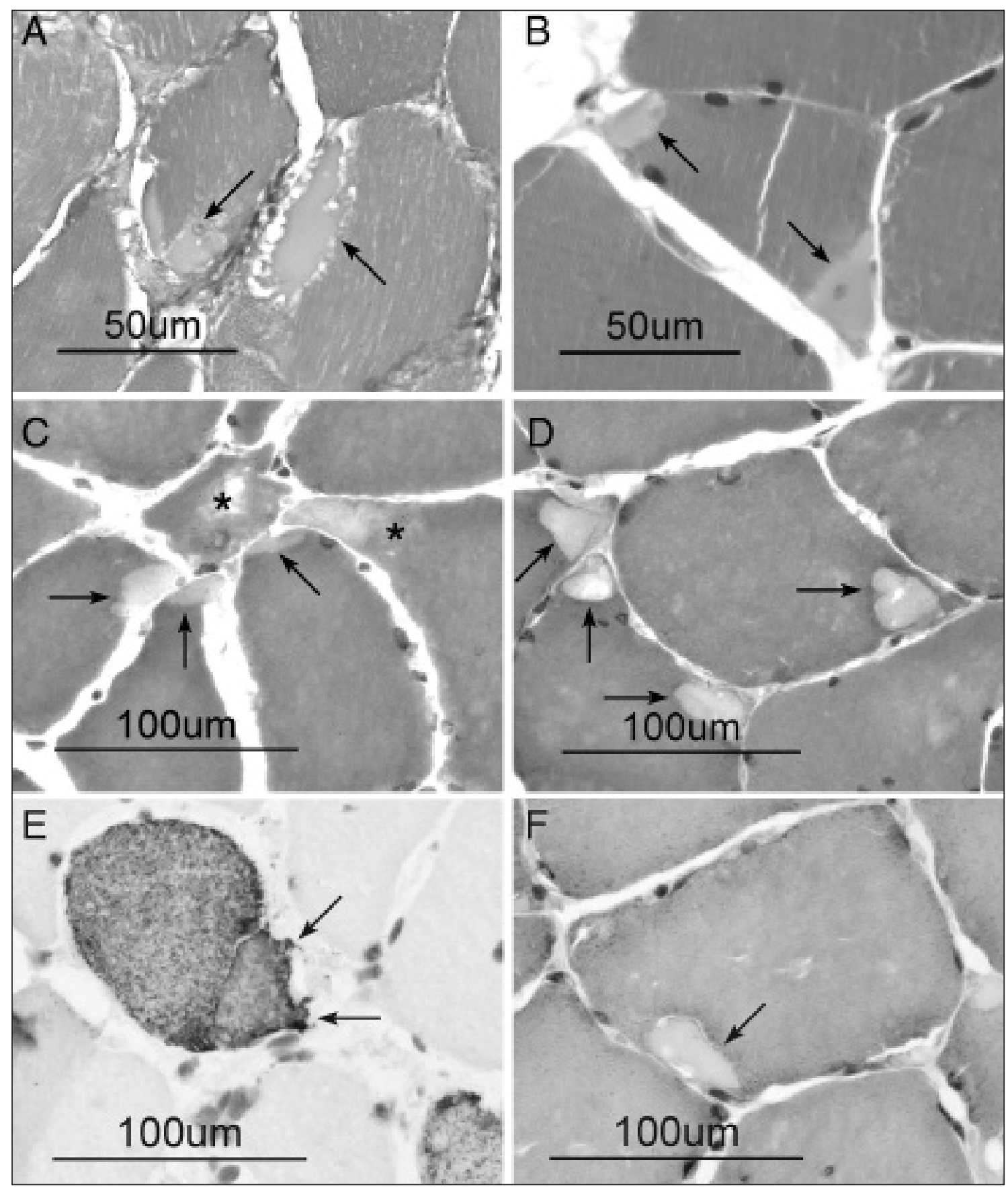

Figure: (A and B) Hyaline bodies (arrows), typically adjacent to the sarcolemma, are seen in the 1954 (A) and 1960 (B) muscle biopsies. ( $C$ and D) Discrete hyaline bodies (arrows) are easily found. In addition, some fibers show a mottled smudge-like cytoplasm (star C). Both findings were limited to type I fibers. (E) Hyaline bodies demonstrated immunoreactivity for myosin heavy chain, slow. $(F)$ Mitochondria aggregating in the region of a hyaline body tend to make the margin appear discrete. Figure A PTAH stain, $B, C, D H \& E$ stain, E immunohistochemistry with myosin heavy chain, slow and $F$ histochemistry with the modified Gomori trichrome method

demonstrates an irregular smudge-like ATPase reactivity and these fibers were also abnormal with MHC immunohistochemistry (see above) (Figure C and D). These eosinophilic hyaline areas or bodies failed to react or stain with modified Gomori trichrome, Periodic acid Schiff, oxidative enzymes, Oil red O, Congo Red, and ATPase at pH 9.4.
However, the hyaline bodies were intensely dark with the ATPase preincubated at $\mathrm{pH}$ 4.2. Hyaline bodies tended to be marginated by mitochondria and glycogen. (Figure F).

The immunohistochemical studies showed intense staining of hyaline bodies with slow MHC but not with any of the other myosin 
antibodies. Occasional disorganized fibers showed an irregular pattern of cytoplasmic reactivity for slow MHC (Figure E). Hyaline bodies failed to react with any other MHC antibodies. They tended to be marginated or outlined by desmin immunoreactivity.

Electron microscopy showed the hyaline bodies to consist of a fairly uniform, finely granular material, which was not membrane bound. At the margins the granular material blended with the myofibrillary elements. The disorganized fibers showed the same granular material dividing the myofibrillary network and appearing to "lysis" to muscle cell cytoplasm.

\section{Discussion}

Congenital myopathies have been characterized, in general, on the basis of histopathological findings. A spectrum of congenital myopathies is still emerging with diverse clinical, pathological and genetic abnormalities. Gene defects and mutant proteins have been identified for several congenital myopathies namely nemaline myopathy, central core disease, desminopathy and actin related myopathies. ${ }^{12}$ However, the genetic background of the majority of congenital myopathies is still being elucidated.

Hyaline body myopathy is also a well-characterized but rare congenital myopathy. Recently two causative genes have been identified in patients with $\mathrm{HBM}^{8,9}$. Earlier reports suggest autosomal recessive inheritance, ${ }^{2}$ however, autosomal dominant inheritance is strongly favored by the two largest published family pedigrees. ${ }^{6,7}$ In our patient the case is most likely sporadic, though one is left wondering about the exact cause of the pediatric death of two paternal uncles.

Clinically, hyaline body myopathy is characterized by onset either early in childhood with generalized weakness accentuated proximally or in adulthood with scapuloperoneal distribution of weakness. ${ }^{2-6}$ A recently published report describes two patterns of presentation: a mild nonprogressive disease and a severe progressive disease with onset in early childhood. ${ }^{7}$

Our patient had onset early in childhood with limb girdle distribution of weakness and no progression initially during early childhood years. Later in adulthood, following a period of stability, progressive worsening was noticed. This suggests a third pattern of presentation consisting of childhood onset nonprogressive disease with later adulthood progression. In addition, one of the major presenting features in our patient was severe aching pain in the affected muscles during adulthood. Hypertrophy of the calf muscles was also noted. Muscles were nontender on examination with no evidence of myotonia on electrophysiology and muscle pathology failed to reveal any evidence of inflammation. Similar distribution of weakness and hypertrophy has been reported earlier. However, none of the patients described earlier with HBM were reported to have pain.

The characteristic histopathologic features were first described by Cancilla et al, ${ }^{2}$ which were subsequently described as hyaline bodies. ${ }^{1,4}$ Later, Ceuterick et al, ${ }^{5}$ and Masuzugawa et al, ${ }^{6}$ made significant contribution in terms of immunohistochemical qualities of these bodies. However, there was a difference in the antibody staining properties between the two studies. Additionally, immunostaining to desmin was also observed at the periphery of these bodies in both the groups.
Staining characteristics similar to Masuzugawa and colleagues were also found in a recently reported family. ${ }^{6}$ In our study, the hyaline bodies reacted to MHC slow but not to MHC fast. Reactivity to desmin was also found at the borders of hyaline bodies. Our findings are similar to the antibody staining characteristics described by Masuzugawa and colleagues ${ }^{6}$, supporting their suggestion that these hyaline bodies may be degradation products of MHC slow. Goebel and Warlo have suggested that HBM may be considered as a protein surplus myopathy. ${ }^{12,13}$ Protein surplus myopathies refer to the group of myopthies marked by a surplus of proteins present in a granular or filamentous form such as desmin related myopathies and actinopathy. ${ }^{13}$ It is notable that, similar to Bohlega and colleagues, ${ }^{7}$ two earlier biopsies during childhood, also demonstrate presence of hyaline bodies. However, with limited staining possible on earlier biopsied material, it is difficult to determine whether hyaline bodies increased in number or changed morphologically over time.

In conclusion, there appears to be another pattern of presentation with adulthood progression in HBM, which has not been described before. Further case studies are required to understand the genetics and clinical progression of this congenital myopathy.

\section{REFERENCES}

1. Engel AG, Banker BQ. Ultra structural changes in diseased muscle. In: Engel AG, Armstrong CF (Eds). Myology. 2nd ed. New York: McGraw-Hill, 1994: 939-944.

2. Cancilla PA, Kalayanaraman K, Verity MA, Munsat T, Pearson CM. Familial myopathy with probable lysis of myofibrils in type I fibers. Neurology 1971;21:579-585.

3. Sahgal V, Sahgal S. A new congenital myopathy: a morphological, cytochemical and histochemical study. Acta Neuropathol (Berl) 1977;37:225-230.

4. Barohn RJ, Brumback RA, Mendell JR. Hyaline body myopathy. Neuromuscul Disord 1994;4:257-262.

5. Ceuterick C, Martin JJ, Martens C. Hyaline bodies in skeletal muscle of a patient with a mild chronic nonprogressive congenital myopathy. Clin Neuropathol 1993;12:79-83.

6. Masuzugawa S, Kuzuhara S, Narita Y, et al. Autosomal dominant hyaline body myopathy presenting as scapuloperoneal syndrome: clinical features and muscle pathology. Neurology 1997;48:253257.

7. Bohlega S, Lach B, Meyer BF, et al. Autosomal dominant hyaline body myopathy: clinical variability and pathologic findings. Neurology 2003;61:1519-1523.

8. Tajsharghi H, Thornell LE, Lindberg C, et al. Myosin storage myopathy associated with a heterozygous missense mutation in MYH7. Ann Neurol 2003;54:494-500.

9. Onengut S, Ugur SA, Karasoy H, Yuceyar N, Tolun A. Identification of a locus for an autosomal recessive hyaline body myopathy at chromosome 3p22.2-p21.32. Neuromuscul Disord 2004;14:4-9.

10. Chapman CR, Casey KL, Dubner R, et al: Pain measurement: an overview. Pain 1985;22:1-31.

11. Medical Research Council: Aids to the examination of the peripheral nervous system. Memorandum No.45. Her Majesty's Stationary Office, 1976.

12. Goebel HH. Miscellaneous myopathies: rare myopathies of childhood. In: Karpati G (Ed). Structural and Molecular Basis of Skeletal Muscle Diseases. ISN Neuropath. Press, Basel, 2002: 287

13. Goebel HH, Warlo I. Surplus protein myopathies. Neuromuscul Disord 2001;11:3-6. 